ISSN 2236-0859

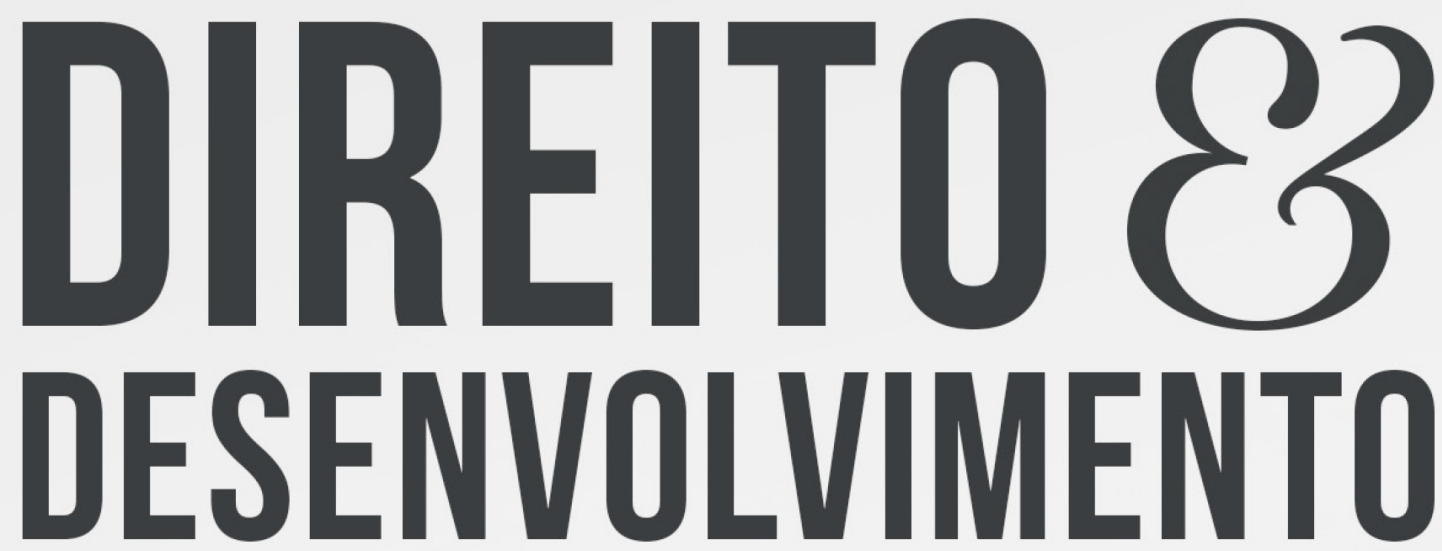

REVISTA DO PROGRAMA DE PÓS-GRADUAÇÃO EM DIREITO MESTRADO EM DIREITO E DESENVOLVIMENTO SUSTENTÁVEL

O MITO DA DEMOCRACIA DIGITAL NO BRASIL

TASSIA TEIXEIRA DE FREITAS BIANCO ERBANO CAVALLI

CHARLES EMANUEL PARCHEN

CINTHIA OBLADEN DE ALMENDRA FREITAS 


\title{
O MITO DA DEMOCRACIA DIGITAL NO BRASIL
}

\section{THE MYTH OF DIGITAL DEMOCRACY IN BRAZIL}

Recebido: 30/09/2020

Aprovado: 19/05/2021
Tassia Teixeira de Freitas Bianco Erbano Cavalli

Charles Emanuel Parchen ${ }^{2}$

Cinthia Obladen de Almendra Freitas ${ }^{3}$

\section{RESUMO:}

O debate político ocorre em diversos meios, incluindo redes sociais, as quais, por meio da utilização de algoritmos, alcançam inúmeras pessoas, o que causa profundas mudanças na democracia representativa. Com o uso das Tecnologias da Informação e Comunicação (TIC's), surge um cidadão que se manifesta na Internet e as redes sociais surgem como meios que instrumentalizam novas possibilidades. A partir dessa movimentação na Internet o cidadão conectado exerce a chamada democracia digital. Necessário analisar se a tecnologia de fato expande as liberdades dos indivíduos e o desenvolvimento dos países baseados na democracia ou será apenas um mito, modificando o espaço das manipulações. O artigo analisa se de fato está-se diante de uma nova possibilidade ou se os cidadãos estão sendo apenas utilizados como fonte de dados, induzidos a reproduzir conteúdo. $\mathrm{O}$ trabalho de pesquisa seguiu o método dedutivo, passando pela fase exploratória, abordando a formação de uma democracia no espaço digital, de modo que as TIC's transformaram de maneira significativa a participação do cidadão na vida política e democrática. A Internet deve proporcionar transparência e participação popular, num ambiente propício ao debate público, neutro e seguro. Caso contrário, está-se diante apenas de uma nova ferramenta de manipulação do cidadão.

Palavras-chave: Tecnologia da informação e Comunicação. Democracia Digital. Sociedades em Rede. Manipulação de Informação. Direitos Fundamentais.

\begin{abstract}
:
Political debate takes place in many kinds of medias, including social networks, which, through the use of algorithms, reach countless people, causing profound changes in representative democracy. With the use of Information and Communication Technology, a citizen emerges manifesting itself on the Internet and social networks emerge as means that instrumentalize new possibilities. From this movement on the Internet the connected citizen exercises the so-called digital democracy. It is necessary to analyze whether technology actually expands the freedoms of individuals and the development of countries based on democracy or if is just a myth, modifying the space of manipulation. The article analyzes whether it is in fact a new possibility or whether

1 Doutoranda em Direito pela Pontifícia Universidade Católica do Paraná (PUCPR), área de concentração: Direito Socioambiental e Sustentabilidade. Mestre em Direito pela PUCPR, advogada e professora universitária. Bolsista PUCPR. Email: tassia_erbano@ yahoo.com.br

2 Doutorando em Direito PUCPR, área de concentração: Direito Socioambiental e Sustentabilidade. Mestre em Direito pela PUCPR, advogado, professor dos Cursos de Direito e de Administração de Empresas do Centro Universitário Curitiba - Unicuritiba (CuritibaPR) e do Curso de Direito da Faculdade Santa Cruz (Curitiba-PR). Bolsista CAPES. Email: charlesadv@gmail.com

3 Doutora em Informática pela Pontifícia Universidade Católica do Paraná. Professora Titular da PUCPR da Escola de Direito. Professora Permanente do Programa de Pós-Graduação em Direito Econômico e Socioambiental da PUCPR (Curitiba/PR-Brasil). Membro Consultivo da Comissão de Inovação e Gestão da OAB-PR. Email: cinthia.freitas@pucpr.br
\end{abstract}


citizens are only being used as a data source, induced to reproduce content. The research work followed the deductive method, going through the exploratory phase, addressing the formation of a democracy in the digital space, so that ICTs significantly transformed citizen participation in political and democratic life. The Internet must provide transparency and popular participation in an environment that is conducive to public, neutral and secure debate. Otherwise, it is just a new tool for manipulating the citizen.

Keywords: Information Technology and Communication. Digital Democracy. Networking Societies. Information Manipulation. Fundamental Rights.

\section{INTRODUÇÃO}

As tecnologias surgem com o propósito de facilitar a vida de todos. Sendo o ser humano facilmente adaptável às facilidades, recebe muito bem qualquer conforto advindo das TIC's (Tecnologias da Informação e Comunicação). Tais tecnologias possibilitaram a criação de redes sociais em que se propagam notícias e posicionamentos de seus usuários, fazendo surgir um novo sujeito "político-tecno-social" (PAMPLONA; FREITAS, 2015, p. 99-101), o qual tem acesso a informação veiculada digitalmente e vontade de participar do debate público e das decisões públicas.

Assim, num primeiro vislumbra-se um outro ambiente para discussões, debates e expansão de liberdades, sem limites de espaço, tempo ou distâncias. Porém, as redes sociais não são um espaço de debates, mas sim de propagação de voz dos usuários sem realmente existir ouvinte. Ou seja, fala-se muito, ouve-se pouco. Eis aqui o cenário de fundo da discussão do artigo.

Bauman (2000, p. 11), analisando "em busca do espaço público", faz uma análise bastante interessante acerca dos motivos que levam as pessoas às ruas em manifestações, como se mesmo sem conhecer profundamente dos fatos, possuem a vontade fazer algo a respeito. E não apenas fazer, mas para que outros também vejam seus atos, como uma sensação de motivação comunitária.

Enquanto isso acontece, tem-se o favorecimento da personalização, com algoritmos e sensores que recolhem novos sinais pessoais e fluxos de dados de cada usuário da Internet. Questiona-se: será a tecnologia, coligada ao conhecimento e propagação de informações, uma aliada na expansão das liberdades dos indivíduos e desenvolvimento dos países baseados na democracia ou será apenas um mito, modificando somente o espaço das discussões e manipulações, sem sanar antigos problemas da sociedade? E, ainda, tendo como realidade brasileira o não acesso por todos à rede mundial de computadores, seria essa uma barreira para a concretização da democracia digital? Incluir todos no debate e na formação dessa democracia na era da globalização e novas tecnologias é fundamental. Mas será isto suficiente?

Cada busca realizada ou cada notícia no feed dos usuários gera uma nova experiência que leva a algo, seja um site, novas informações sobre alguém, notícias, produtos, serviços, entre outros. Porém, se manipuladas as informações, ao buscar uma informação, o usuário pode ser direcionado a um espaço que não é de sua escolha. E, sendo esse algo, diferente do interesse do usuário, tem-se um problema.

Evidentemente, as novas tecnologias permitem a comunicação instantânea e em tempo real, o que, para Castells (2007, p.186), por exemplo, representa uma oportunidade para materializar o sonho da democracia. Mas para outros, como Hindman (2009, p. 141), dificulta a necessária reflexão sobre os processos políticos nas sociedades modernas, as quais 
se caracterizam pela existência de inúmeros interesses e complexidades que exigem debates públicos aprofundados e períodos de reflexão.

Neste contexto, o artigo analisa a democracia digital, suas características e manipulações existentes, as quais devem ser motivo de atenção por parte do cidadão e até mesmo dos governantes. Para isto, primeiro são realizados apontamentos sobre a formação da democracia digital, posteriormente são analisados problemas não resolvidos em que pese novas tecnologias acerca da participação política e, por fim, apresenta-se o desafio moderno relacionado a democracia e ao meio ambiente digital, uma vez que as redes sociais utilizam dados dos usuários e divulgam notícias de acordo com cada perfil, porém nem sempre com a livre ciência desses, gerando comportamentos e os levando a caminhos diferentes do que, de forma livre, teriam escolhidos após reflexão.

O artigo é resultado de projeto de pesquisa e seguiu o método dedutivo, utilizandose técnica bibliográfica, visando demonstrar que as TIC's podem ser grandes aliadas, se bem utilizadas, a fim de concretizar a democracia representativa no espaço digital, que não é um novo espaço, mas seu uso para exercitar a democracia é algo recente e amplia possibilidades de participação nas sociedades que é informacional e tecnológica. O cenário contempla, que se não forem observados pontos importantes dos processos e tecnologias que permeiam o espaço digital, ao invés de se alcançar a concretização da democracia e expansão de liberdades, ocorrerá apenas comportamentos manipulados para interesse de quem detém poder para uso dos dados dos usuários. A pesquisa tem caráter exploratório e descritivo.

\section{FORMAÇÃO DA DEMOCRACIA DIGITAL}

Antes de adentrar ao tema Democracia Digital, faz-se necessária a análise dos aspectos que permeiam e garantem a democracia. $O$ fundamento de toda autoridade reside na coletividade de cidadãos que, estando representados não têm a responsabilidade direta da gestão dos negócios públicos. A democracia representativa é, então, um sistema de governo que tende a incluir a liberdade na relação política "de maneira tal que, fundada sobre a adesão daqueles que lhe são submissos, ela permanece compatível com a liberdade deles" (CHEVALLIER, 2009, p. 184-185). Porém, os representantes eleitos pelo povo é que são encarregados de agir e decidir em seu nome.

A democracia deve ser vista como garantia de discussão e debate, para que os processos de geração de escolhas sejam bem fundamentados e refletidos. "Esses processos são cruciais para a formação de valores e prioridades, e não podemos, em geral, tomar as preferências como dadas independentemente de discussão pública" (SEN, 2000, p. 180-181).

O termo democracia, defendido por Carlos Santiago Nino (2007, p. 187), aduz que ao passo que se entende como necessário o papel individual no processo de tomada de decisões, não se pode esquecer que se trata de um processo, e como tal, está sujeito às opiniões entre os indivíduos participantes, a fim de satisfazer a maior parcela de indivíduos possível, não se esquecendo de que por vezes a vontade de uma maioria pode infringir questões estabelecidas na Constituição que garante o espaço para diversidade.

Para Robert Dahl a democracia é a melhor opção, já que a democracia evita a tirania, garantindo aos cidadãos direitos essenciais, bem como a liberdade pessoal. Além disso, a democracia leva à autodeterminação e autonomia moral, promovendo o desenvolvimento humano e igualdade política, buscando paz e prosperidade (DAHL, 2011, p. 61-71).

Assim, Dahl institui critérios para o processo democrático, aduzindo que, dentre outras questões, a constituição deve estabelecer as regras e princípios que determinarão como serão 
tomadas as decisões. Além disso, o governo do Estado deverá considerar, todos os membros da comunidade, como politicamente iguais, ou seja, estes devem ser tratados como se estivessem igualmente qualificados para participar do processo de tomada de decisão (DAHL, 2011, p. 47-49).

Com exercício da democracia, cidadãos usufruindo direitos e cumprindo com seus deveres, a liberdade será garantida, de modo mais amplo do que em qualquer outra forma de governo. A democracia representativa é uma ferramenta poderosa de legitimação das ações do governo. A democracia é um bem inquestionável (HIRST, 1992, p. 30).

Com relação à Democracia Digital, percebe-se que o surgimento e criação de novas formas de comunicação lançaram a democracia num espaço de participação inclusiva, nunca antes vista. O cidadão é, ainda que em sua rede social, um ator participativo com sua opinião sendo, diretamente, influenciador e influenciado nesse sistema.

A sociedade está conectada via rede mundial de computadores, a Internet, permitindo a troca de informações de uma maneira que atinge a qualquer um "conectado" no globo terrestre. Está-se diante de uma sociedade voltada à velocidade, acessibilidade, disponibilidade e mobilidade, "visto que foi atingido, por tal sociedade, um estágio de desenvolvimento caracterizado pela capacidade de obter e compartilhar qualquer informação instantaneamente" (PAMPLONA; FREITAS, 2015, p. 92).

Neste contexto, vivencia-se o paradigma atual denominado everyware (GREENFIELD, 2006) ${ }^{4}$, visto que o cidadão está conectado a partir de qualquer lugar em razão da mobilidade das TIC's e sua relação com a Democracia Digital.

Nessa realidade, advinda graças às TIC's, surge um indivíduo que se apresenta político nas redes sociais, estabelecendo uma relação entre três elementos básicos, quais sejam: "a política, a tecnologia e as redes sociais" (PAMPLONA; FREITAS, 2015, p. 94). Com esses elementos, tem-se uma relação cada vez mais "presente nos mais variados e numerosos lugares do mundo quando comparados aos métodos convencionais (monitor, teclado, mouse)" (PAMPLONA; FREITAS, 2015, p. 94), por isso, "em todo lugar".

Foi com o surgimento da Internet se que criou um espaço digital sem fronteiras, em que circulam milhares de informações veiculadas na rede de computadores e a Internet se estabeleceu como um meio para toda e qualquer modalidade de ação das pessoas.

Além disto, cabe destacar que ao se comunicar por meio da Internet, inclusive por meio das redes sociais, as conexões entre usuários são exponenciais devido à característica técnica de que a partir de um usuário derivam-se novas conexões. Assim, todos os que estão interligados ao usuário que também possui outros contatos, fazem com que tudo que é postado seja rapidamente espalhado (FREITAS, 2015, p. 8o).

Aqui tem-se a confluência de duas redes: a Internet e as redes sociais. A estrutura da rede social é o elemento "cuja principal característica é a exposição pública da rede dos atores, que permite mais facilmente divisar a diferença entre esse tipo de site e outras formas de comunicação mediada pelo computador" (RECUERO, 2009, p. 121). Segundo Castells (1999, p. 498), as redes são "um conjunto de nós interconectados. Nó é o ponto no qual uma curva se entrecorta. Concretamente, o que um nó é depende do tipo de redes concretas de que falamos". Ou seja, são padrões de contato criados pelo fluxo de mensagens entre usuários no tempo e no espaço, tornando as formas organizacionais mais eficientes como resultado das características inerentes à rede, quais sejam: flexibilidade, escalabilidade e sobrevivência.

4 No paradigma everyware, todas as informações que procuramos agora para nossos telefones ou navegadores da Web se tornam acessíveis de praticamente qualquer lugar, a qualquer momento e são entregues de maneira apropriada à nossa localização e contexto. Texto original: "In everyware, all the information we now look to our phones or Web browsers to provide becomes accessible from just about anywhere, at any time, and is delivered in a manner appropriate to our location and context". 
Em um contexto de crescimento das TIC's relacionadas ao desenvolvimento dos computadores e da consequente reestruturação dos limites de espaço e de tempo e, ainda, da criação de novos locais de debates, logo surgiram temas ligados à democracia em ambientes digitais.

Tendo em vista que na sociedade informacional tudo o que é feito pelo usuário pode e é compartilhado, nas redes sociais de modo que tudo que se refere a cada indivíduo também se refere ao ciberespaço, visto que a sociabilidade se realiza neste espaço sem fronteiras ou demarcações.

Atualmente, o debate político e até mesmo estratégias políticas ocorrem em mídias de comunicação que alcançam as grandes massas.

Um exemplo no Brasil aconteceu quando dos movimentos ${ }^{5}$ originados na Internet, em 2013 e 2015, que culminaram, dentre outros motivos, no Impeachment da Presidente da República Dilma Russef. Nas ruas era possível ver inúmeras causas sendo levantadas sem conexão direta entre elas, mas os participantes tinham algo em comum: haviam recebidos em seus feeds nas redes sociais convites sobre o evento, conforme perfil de cada usuário.

O ápice de tal movimento aludido ocorreu no dia 17 de junho de 2013, em que foram registradas inúmeras manifestações populares com adesão de milhares de participantes em grandes cidades brasileiras (MPL) ${ }^{6}$. No Brasil, foram contabilizadas 353 cidades envolvidas com as manifestações, advindas, sua organização, do Facebook e Twitter, utilizados intensamente para articular os protestos, divulgando hora e local com "hashtags" (etiquetas de postagens pelos usuários para facilitar a busca).

Mesmo diante das manifestações, após as eleições, diversas cadeiras políticas permaneceram intactas. Após a consolidação do resultado, as redes sociais foram novamente fomentadas.7 Dia 15 de março de 2015, milhões de pessoas foram às ruas. Necessário destacar que o grupo em questão não era homogêneo nas suas pautas e, entre outros fatores que influenciaram a manifestação, existiam pedidos de investigação da corrupção.

As redes sociais foram fundamentais para a convocação de milhares de pessoas à manifestação. Tal fato é uma prova das mudanças radicais que a Internet pode produzir. Percebeu-se uma organização de movimentos de massa sem estarem necessariamente vinculados previamente aos manifestantes, seja mediante associações, sindicatos ou partidos políticos.

De qualquer forma, dentro das premissas elencadas como necessárias para a consolidação de um modelo democrático baseado nas facilidades decorrentes da rede mundial de computadores, tem-se que atualmente a democracia digital é uma possibilidade que deve ser seriamente avaliada.

É necessário, para existir uma verdadeira democracia no mundo digital, que haja não apenas o acesso à informação, mas a sua efetiva democratização e uso sem influências que possam manipular a vontade dos usuários. Sem isto, não se está diante de uma democracia verdadeira, ainda que no âmbito digital.

\footnotetext{
5 À guisa de exemplo, o ápice do movimento acima aludido ocorreu no dia 17 de junho de 2013, em que foram registradas inúmeras manifestações populares com adesão de milhares de participantes em grandes cidades brasileiras. No Brasil, foram contabilizadas 353 cidades envolvidas com as manifestações, advindas, sua organização, do Facebook e Twitter, utilizados intensamente para articular os protestos, divulgando hora e local com "hashtags" (etiquetas de postagens pelos usuários para facilitar a busca). Mesmo diante das manifestações, após as eleições, em segundo turno, Dilma Rousseff foi reeleita. Após a consolidação do resultado, as redes sociais foram novamente fomentadas, para fins de organizar uma grande mobilização nacional contra a presidente reeleita. Dia 15 de março de 2015, milhões de pessoas foram às ruas. Necessário destacar que outros fatores influenciaram a manifestação, como a investigação da corrupção. MPL. Movimento Passe Livre. Sobre. Disponível em: < https://www.facebook.com/passelivresp>. Acesso em: o2 dez. 2019; MBL. Movimento Brasil Livre. Sobre. Disponível em: <http://www.movimentobrasillivre.org/>. Acesso em: o2 dez. 2019; MOVIMENTO Vem Pra Rua. Sobre. Disponível em: <http://vemprarua.net>. Acesso em: o2 dez. 2019.

6 MPL. Movimento Passe Livre. Sobre. Disponível em: < https://www.facebook.com/passelivresp>. Acesso em: 02 dez. 2019.

7 MBL. Movimento Brasil Livre. Sobre. Disponível em: <http://www.movimentobrasillivre.org/>.

Acesso em: o2 de dez. de 2019; MOVIMENTO Vem Pra Rua. Sobre. Disponível em: <http://vemprarua.net>. Acesso em: 02 dez. 2019.
} 


\section{NOVAS TECNOLOGIAS, PROBLEMAS ANTIGOS}

Atualmente, o debate político e até mesmo estratégias políticas ocorrem em mídias de comunicação que alcançam as grandes massas. Nos últimos anos as redes sociais foram relevantes na formação da opinião política, culminando em mudanças na democracia representativa.

Nesse contexto, existem estruturas que surgiram na Internet. Um exemplo é o portal, em funcionamento desde 2009, denominado "e-democracia" (BRASIL, 20-?) ${ }^{8}$ elaborado pela Câmara dos Deputados. O objetivo do portal é fomentar a participação das pessoas nos debates que insurgem na Câmara dos Deputados, assim, por meio dessa plataforma, qualquer cidadão pode efetuar o cadastramento e utilizar o portal para iniciar, mediar e participar de alguma discussão relacionada a algum projeto de lei em tramitação. Os debates são acompanhados pelos deputados federais e assim, possuem um "potencial transformador da realidade" (PAMPLONA; FREITAS, 2015, p. 99-101).

Ou seja, ainda que existam distâncias, a Internet é uma ferramenta de aproximação de pessoas e exercício efetivo de democracia no mundo digital. Importante destacar que o portal disponibiliza relatórios dos resultados das discussões, com o número de tópicos, mensagens recebidas, membros, visualizações, número de postagens, os membros mais ativos, entre outros. Inclusive, permite no caso do "wikilégis" os relatórios das alterações e sugestões de cada projeto submetido. Por fim, destaca-se que o portal apresenta o número de usuários cadastrados pelo filtro da "unidade da Federação" (PAMPLONA; FREITAS, 2015, p. 99-101). Mas para o exercício efetivo da democracia no mundo digital são necessários investimentos em educação, incluindo capacitação de todo e qualquer cidadão ao uso de ferramentas tecnológicas (computador, tablets, celulares, Internet, entre outros), bem como acesso e uso responsável de tais tecnologias. Veja-se que sem estrutura e educação, têm-se novas tecnologias, porém, antigos problemas continuam existindo, acarretando no baixo uso da plataforma.

Conforme Castells (2007, p. 186) aduz, um dia a Internet pode ser um instrumento ideal para fomentar a democracia, e isso ainda pode acontecer. Porém, sem investimento no usuário, com educação e recursos, de nada adianta o investimento apenas no desenvolvimento de plataformas digitais, pois seu fim não será atingido, qual seja, participação ativa do cidadão.

Além do mais, é notório que ainda existe um número relevante de pessoas que vivem sem condições mínimas de sobrevivência e, portanto, sem quaisquer condições de acesso à Internet. ${ }^{9}$ Assim, questiona-se a viabilidade e o acesso a todos à rede mundial de computadores. Seria essa uma barreira para a concretização da democracia digital? Incluir todos no debate e na formação dessa democracia na era da globalização e de novas tecnologias é fundamental. Mas seria também isso suficiente?

Percebe-se, por outro lado, a existência dos info-excluídos ${ }^{10}$. Ou seja, sujeitos que não possuem condições de acesso à Internet e os que possuem, mas não têm condições e familiaridade com as plataformas que dão suporte à Democracia Digital. Sem esse suporte, o cidadão sequer tem conhecimento dos riscos a que se expõe ao ingressar em redes sociais e ao ser bombardeado de informações que talvez sequer consiga discernir, mudando seu comportamento de consumo, relacionamento, familiar e até mesmo político.

\footnotetext{
8 BRASIL. Câmara dos Deputados. E-Democracia. Sobre o portal e-democracia. Disponível em: <http://arquivo.edemocracia. camara.leg.br/web/public/o-que-e\#.WOEzKgIrLbo>. Acesso em: o2 dez. 2019.

9 Dados da Comissão Econômica para a América Latina e o Caribe - CEPAL (2015) apontam que a partir de 2012 houve aumento no número de pessoas que vivem em situação de extrema pobreza no Brasil, passando de 5,4\% da população nacional em 2012 para 5,9\% em 2013. NAÇÕES UNIDAS. Comissão Econômica para a América Latina e o Caribe. CEPAL. Panorama Social da América Latina. Síntese. 2014. Disponível em: <https://repositorio.cepal.org/bitstream/handle/11362/37706/1/S1420848_pt.pdf>. Acesso em: o2 dez. 2019.

10 Grupo de excluídos das Tecnologias da Informação e Comunicação e redes globais.
} 
No entanto, cada vez mais as tecnologias estão acessíveis, de modo que se houverem, de um lado, políticas públicas pelo Estado de acesso às novas tecnologias e educação acerca da democracia e, de outro, interesse pelos cidadãos do uso de tais tecnologias e engajamento no processo democrático, o novo espaço além de viável tornar-se-á possível. Afinal, as ferramentas para o uso das redes sociais e portais como "e-democracia" são de fácil acesso, desde que o cidadão esteja preparado e capaz de utilizar instrumentos tecnológicos. Deve-se ter em mente que existe previsão legal no intuito da inclusão digital. ${ }^{11}$ Portanto, para a concretização da democracia digital necessita-se de alicerces e efetividade de direitos, a exemplo, da liberdade de expressão. Sem transparência no processo e igualdade não é possível, ainda que todos migrem ao campo digital, vivenciar a democracia.

Sob a falsa sensação de maior liberdade de expressão na Internet, neutralidade da rede e privacidade (premissas básicas do Marco Civil da Internet [BRASIL, 2014]) ${ }^{12}$, ainda assim, não há clareza quanto a alguns dispositivos, deixando, de certa forma, os usuários à mercê de comportamentos sob a influência dos algoritmos. Não há controle ou fiscalização específica nesse sentido. Mesmo assim, deve-se buscar construir um ambiente efetivamente democrático na rede.

Evidentemente que a democracia digital não é a resposta para todos os males da sociedade nem a solução para a inclusão total, afinal, mesmo fora da democracia digital não existe engajamento e participação de cem por cento dos cidadãos. Mas, seria essa uma forma de proporcionar um incremento da participação política que poderia impactar a ponto de reconstruir as noções de democracia conhecidas em um ambiente de efetiva troca democrática e de realização dos direitos fundamentais? Mesmo que não existam info-excluídos, em um mundo ideal, ainda assim a Internet proporcionaria a Democracia de forma plena? Ou a Democracia Digital é apenas um mito?

\section{REDES SOCIAIS E O MITO DA DEMOCRACIA DIGITAL NO BRASIL}

A Internet possui características técnicas (estrutura e topologia) e sociais com potencial para promover interação, debates e aspectos políticos de maneira mais franca. Isto devido a estrutura descentralizada o que pode por promover um debate mais aberto, sem mediações s e sujeições à apropriação por um ou outro grupo de interesse.

Assim, teoricamente, as TIC's são um meio de concretização dos processos democráticos, considerando-se a popularização da Internet e das redes sociais, propriamente ditas. Eli Pariser

11 Lei 12.965/2014:

Art. 26. O cumprimento do dever constitucional do Estado na prestação da educação, em todos os níveis de ensino, inclui a capacitação, integrada a outras práticas educacionais, para o uso seguro, consciente e responsável da Internet como ferramenta para o exercício da cidadania, a promoção da cultura e o desenvolvimento tecnológico.

Art. 27. As iniciativas públicas de fomento à cultura digital e de promoção da Internet como ferramenta social devem: I - promover a inclusão digital; II - buscar reduzir as desigualdades, sobretudo entre as diferentes regiões do País, no acesso às tecnologias da informação e comunicação e no seu uso; e III - fomentar a produção e circulação de conteúdo nacional.

Art. 28. O Estado deve, periodicamente, formular e fomentar estudos, bem como fixar metas, estratégias, planos e cronogramas, referentes ao uso e desenvolvimento da Internet no País.

12 Art. $3^{\circ}$ A disciplina do uso da Internet no Brasil tem os seguintes princípios: I - garantia da liberdade de expressão, comunicação e manifestação de pensamento, nos termos da Constituição Federal; II - proteção da privacidade; III - proteção dos dados pessoais, na forma da lei; IV - preservação e garantia da neutralidade de rede; V - preservação da estabilidade, segurança e funcionalidade da rede, por meio de medidas técnicas compatíveis com os padrões internacionais e pelo estímulo ao uso de boas práticas; VI - responsabilização dos agentes de acordo com suas atividades, nos termos da lei; VII - preservação da natureza participativa da rede; VIII - liberdade dos modelos de negócios promovidos na Internet, desde que não conflitem com os demais princípios estabelecidos nesta Lei. Parágrafo único. Os princípios expressos nesta Lei não excluem outros previstos no ordenamento jurídico pátrio relacionados à matéria ou nos tratados internacionais em que a República Federativa do Brasil seja parte. Art. $4^{\circ}$ A disciplina do uso da Internet no Brasil tem por objetivo a promoção: I - do direito de acesso à Internet a todos; II - do acesso à informação, ao conhecimento e à participação na vida cultural e na condução dos assuntos públicos; III - da inovação e do fomento à ampla difusão de novas tecnologias e modelos de uso e acesso; e IV - da adesão a padrões tecnológicos abertos que permitam a comunicação, a acessibilidade e a interoperabilidade entre aplicações e bases de dados. 
coaduna com esse entendimento ao afirmar que a Internet é "meio melhor para a democracia do que a imprensa tradicional, com seus fluxos unidirecionais de informação", ressaltando ainda, que a liberdade de imprensa hoje pertence a todos (PARISER, 2012, p. 70).

No entanto, tais afirmações precisam ser repensadas. Existem questões a serem analisadas, afinal, foi a Internet importante para fortalecer e incrementar a participação do cidadão em questões políticas e democráticas? A Internet promove o debate? A audiência online é mais descentralizada do que na mídia tradicional? Os cidadãos têm voz e são ouvidos? Aqueles que chegam a serem ouvidos geram uma reflexão mais profunda ao grande público? ${ }^{\text {?3 }}$ Ou apenas vive-se em pequenas bolhas informacionais individualizadas?

É válido ressaltar que software e hardware não são humanos, porém, algoritmos podem ter acesso a todo o conjunto de dados pessoais que existe online de um usuário. Qual a consequência disso? Os algoritmos sabem mais sobre uma pessoa do que seus próprios familiares. E, à medida em que o Big Data trabalha associado às técnicas de tratamento de dados, tem-se a capacidade de influenciar comportamentos. Assim, as redes sociais funcionam muitas vezes como outdoors com publicidade de produtos e serviços, mas também atuam na esfera política sendo que movimentos políticos as aproveitam e também as utilizam. Assim, têm-se verdadeiros anúncios em espaços sociais dos mais variados assuntos. Desde sites de relacionamento, produtos versus compras até propagação de ideias políticas e indicação de candidatos.

Nesse aspecto, tem-se a questão dos algoritmos que direcionam, a partir de dados dos usuários, suas pesquisas e navegações em sites de relacionamento, pesquisa e serviços.

Mas qual seria então, de fato, o problema? Parte do problema é que as empresas não são obrigadas a explicar como são feitas as decisões que direcionam os algoritmos e, consequentemente, como as informações de aplicativos, sites etc., chegam até os usuários. Veja-se que os usuários são rotulados por seus perfis e direcionados sem nem ao menos saber as razões disso.

Analisando fenômenos naturais, é possível prever acontecimentos como as chuvas, marés, até mesmo eclipses. Mas o que os algoritmos fazem é aplicar a previsibilidade em algo imprevisível muitas vezes: o comportamento humano. Tal fato pode ser perigoso já que a "indução logarítmica pode levar a uma espécie de determinismo informático, no qual os nossos cliques passados decidem inteiramente o nosso futuro". Resumindo, a partir de históricos de navegação na Internet, os usuários sempre irão receber resultados conforme o perfil traçado, sem analisar opiniões que talvez, em primeiro momento fossem contrárias às suas, mas que possibilitariam debates, reflexões e possibilidade de mudança de comportamento por livre convencimento após todo esse processo. Ao contrário, usuários recebem apenas informações sujeitas à sua prévia aprovação, até mesmo manipuladas (fake news) ${ }^{14}$ os quais muitas vezes, após análise do perfil, poderão direcionar comportamentos, inclusive políticos (PARISER, 2012, p. 93).

O que faz das notícias falsas uma preocupação é que tal prática submetida à velocidade do mundo digital transforma a desinformação em escalas nunca antes vistas, atingindo inúmeras pessoas, afetando a democracia diretamente, pois no atual cenário político mundial conflituoso e insegurança jurídica se vive a era da "pós-verdade". Esta palavra adveio de

13 Texto original: "Framed in this way, broad questions about democratization can be broken down into a series of smaller, and ultimately answerable, questions. Some of these deal with political voice as traditionally conceived: Are there types of political participation that have been increased by the Internet? Have significant numbers of previously inactive citizens been recruited in to political activism? Other questions deal with claims that the Internet will challenge vested political interests, encourage public debate, or even blur traditional distinctions between elites and the mass public. Exactly how open is the architecture of the Internet? Are online audiences more decentralized than audiences in traditional media? How many citizens end up getting heard in cyberspace? Are those who end up getting heard a more accurate reflection of broader public?". HINDMAN, Matthew. The myth of digital democracy. Princeton: Princeton University Press, 2009, p. 8.

14 Tradução do termo: Notícias falsas. 
atitudes do Presidente Donal Trump e foi eleita pelo Dicionário Oxford de Inglês, como sendo a palavra do ano de 2016 (OXFORD, s.p.) ${ }^{15}$, relacionando-se ou denotando circunstâncias nas quais os fatos objetivos são menos influentes na formação da opinião pública do que os apelos à emoção e à crença pessoal. Nesta era da política pós-verdade, é fácil selecionar dados e chegar a qualquer conclusão que você deseje. Alguns comentaristas observaram que esta-se vivendo uma era pós-verdade.

Analisando, é possível constatar algumas possibilidades, dentre as quais: cidadão entendendo ser a Internet um ambiente propício à pesquisa neutra, busca um candidato para as próximas eleições. Esse não será direcionado para todas as possibilidades, mas sim, apenas as que o algoritmo julga compatível com sua opinião, cerceando, sem o usuário saber, as informações da rede. Ou ainda, por interesses escusos das empresas que monopolizam sites de busca, as informações que ali aparecem excluem ou até mesmo denigrem determinado candidato, sejam por, inclusive fake news. Como os usuários vão saber?

Atualmente vive-se numa sociedade cada vez mais algorítmica. Portanto, faz-se necessário reconhecer que valores sociais como a justiça, a liberdade e a oportunidade estão intrinsecamente ligados ao modo como o código é escrito e ao tipo de solução que ele oferece. Uma vez compreendido esse fato, pode-se começar a decidir a quais variáveis serão dadas mais importância e a encontrar soluções diferentes.

Porém, se os cidadãos não prestarem atenção no que o algoritmo faz, o resultado poderá ser o oposto do esperado, não se tendo um código "neutro".

É necessário que haja, ainda que de forma básica, uma alfabetização algorítmica. Os cidadãos terão que julgar cada vez mais sistemas informáticos que afetam a sua vida e sua participação democrática. E isso não é impossível. Precisa-se burlar os filtros que modificam o comportamento quando seus resultados não são desejados (PARISER, 2012, p. 159).

Veja-se que o homem não refletiu para se adaptar a tais tecnologias a fim de ter ciência que muitas vezes poderia ser conduzido a sites e informações sem notar. Ele apenas foi inserido nesse novo mundo.

Algumas ferramentas de busca monopolizam ou outros serviços utilizados por usuários agem como bem entendem. E a as pessoas utilizam-se de ferramentas sem ao menos questionar suas identidades, personalidades, desejos, que agora são dados e objetos de mercado. O poder público não dá respostas aos usuários sobre sua privacidade e cuidados nesse sentido, passando o cidadão a viver sob a vigilância constante de empresas que os exploram sem qualquer responsabilidade (VAIDHYANATHAN, 2011, p. 50).

Há uma possível violação de direitos como privacidade, liberdade de expressão e de informação, participação política dos cidadãos se algumas hipóteses acerca do uso dos algoritmos se verificarem.

Diante dessa grande problemática envolvendo a Internet bem como riscos a direitos fundamentais, questiona-se se, ainda que os cidadãos tenham acesso à rede e aparelhos necessários para seu acesso, ainda que tenham a educação e instrução necessárias para utilizar tais recursos, ainda assim, seria possível acreditar que a Internet é um veículo para a efetivação de uma democracia plena?

Afinal, "em alguns casos, deixar que algoritmos tomem decisões sobre aquilo que vemos e as oportunidades que recebemos gera resultados mais justos" (PARISER, 2012, p. 89). A programação de um computador para que ignore completamente fatores como raça e sexo de um ser humano, só é possível se aquela for realizada com precisão, mas ainda assim, existe a

15 Texto original: "Relating to or denoting circumstances in which objective facts are less influential in shaping public opinion than appeals to emotion and personal belief. In this era of post-truth politics, it's easy to cherry-pick data and come to whatever conclusion you desire. Some commentators have observed that we are living in a post-truth age". OXFORD Living Dictionaries. Definition of post-truth. Disponível em: <https://en.oxforddictionaries.com/definition/post-truth>. Acesso em: 02 dez. 2019. 
possibilidade da programação para refletir os costumes sociais da cultura e, assim, representar uma regressão à norma social (PARISER, 2012, p. 89).

Parece que o poder está na mão dos usuários já que se tem uma quantidade muito maior de escolhas sobre a mídia que se consume, mas os usuários não detêm o poder (PARISER, 2012, p. 58). Veja-se que a Internet parece ser cada vez mais um monopólio, afinal, "seja qual for a noção anterior, de que a Internet, por sua natureza, estava imune à monopolização, o presente já deixou claro a loucura do excesso de otimismo. O Ciclo mais uma vez está em movimento" (WU, 2012, p. 327).

Tim Wu traça um paralelo importante sobre as grandes empresas de tecnologia, como a Apple e a Google, afirmando que ambas ainda possuem um foco em alguns mercados, a primeira em players e downloads de músicas e o segundo como ferramenta de busca. Formando um conjunto com o Facebook e a Amazon, eles ditaram a forma como a Internet iria se comportar nos anos 2010, se afastando na noção de uma "rede igual", e assim, consolidou-se também para o futuro a indústria monopolista que caracterizou o século XX (WU, 2012, p. 327-328).

Assim, por essa razão já se percebe um problema quando se associa Internet e democracia. Afinal, se há um monopólio, e existem tecnologias capazes de selecionar os resultados de buscas na Internet para usuários de tal ferramenta, no momento em que uma das empresas que detém tal tecnologia e monopólio pode apoiar determinado candidato, conforme seus interesses, bloqueando informações nas buscas e mostrando outras quando de momentos de processos eleitorais, simplesmente acionando mecanismos de buscas e algoritmos, percebese que há uma afronta aos direitos dos usuários. Selecionar quais informações os usuários terão acesso não é nada democrático. Fere inúmeros direitos fundamentais básicos, tais como o direito a informação, transparência, liberdade, igualdade, criando-se uma falsa sensação de conforto e idoneidade inexistente na Internet. Na curta história do Facebook já se observou a sua força em ajudar e derrubar governos, e se, algum dia, ele buscar alguma vantagem ao se aliar a um governo (como a AT\&T quando forneceu escuta ao presidente George W. Bush), ele poderá ser "um dos melhores instrumentos de espionagem já criados" (WU, 2012, p. 358).

Para atentar-se com a democracia digital no Brasil, ainda mais quando em épocas de eleições, vale analisar o ocorrido nos Estados Unidos da América. A BBC News, em artigo publicado com o título "Como o Facebook pode ter ajudado Trump a ganhar a eleição" (CELLANJONES, 2016, s.p.) explica o funcionamento do Facebook sobre compartilhamento de notícias entre seus usuários em épocas de eleições. Veja-se que nos Estados Unidos da América os jornais declararam apoio a Hillary Clinton ou até mesmo deixaram de divulgar ou apoiar Donald Trump na campanha de 2016 para presidente daquele país. Porém, 156 (cento e cinquenta e seis) milhões de americanos possuíam contas no Facebook e, de acordo com pesquisas, pelo menos dois terços deles usam a rede social como fonte primária de notícias. Nas redes sociais, tais notícias dependem do que cada usuário recebe de seus amigos e seus compartilhamentos bem como seu perfil. Ou seja, pessoas com intenção de voto em Trump recebiam apenas notícias favoráveis de Trump, e o mesmo ocorria com os eleitores de Hillary.

Os jornais traziam ao menos, independente do posicionamento, ideias a favor e contrárias, com opiniões e fontes checadas. Já o Facebook não checa as informações de seus usuários ou notícias compartilhadas. Tão pouco asseguram nas timelines opiniões diversas daquela que o usuário compartilha.

Um exemplo foi durante a campanha presidencial americana de compartilhamento de histórias acusando Hillary de assassinato que apareceram nas páginas de pessoas que declaravam apoio ao candidato Trump. De outro lado, páginas daqueles que apoiavam Hillary, compartilhavam falsa declaração supostamente feita por Trump, em 1998, em que ele chamava eleitores do partido Republicano de burros. 
A grande arma eleitoral dos dois grandes partidos americanos (Democrata e Republicano) foi o Facebook, divulgando e angariando eleitores indecisos. Não é possível afirmar que Trump se elegeu apenas com tal mídia social, porém, tais ferramentas auxiliam indubitavelmente a trazer eleitores indecisos para o lado de quem mais investiu em angariar usuários e espalhar notícias. Afinal, é o Facebook apenas uma rede social ou uma poderosa empresa de mídia?

Sobre o mesmo assunto, a reportagem "BIG DATA: o segredo por trás da eleição de Trump” (ALVES, 2017, s.p.) traz também uma análise bastante interessante acerca do Big Data e a psicologia baseada em dados, sendo a psciometria (ALVES, 2017, s.p.) ${ }^{16}$ (medição de traços psicológicos) a base da nova estratégia eleitoral. Ou seja, tudo que os usuários fazem, online e offline, deixa vestígios digitais (compras, buscas, relacionamentos, curtidas, etc.). A questão é como esses dados são usados. Afinal, o Big Data tem papel principal na estratégia política nos dias de hoje, já que os smartphones são um vasto questionário psicológico preenchido constantemente, consciente e inconscientemente. No entanto, acima de tudo, essa metodologia também funciona no sentido inverso: não só os perfis psicológicos podem ser criados a partir de seus dados, mas essas informações podem ser usadas ao contrário para procurar perfis específicos. Assim, aqueles que detém tal ferramenta poderiam abusar buscando pessoas para manipulá-las. Por exemplo, eleitores indecisos em um processo democrático, influenciando seu voto. Ou seja, é possível utilizar Big Data e psicologia para conquistar eleitorado, por meio das redes sociais e sites de busca.

Cabe a análise da Cambridge Analytica, a qual adquire os dados pessoais de várias fontes, agrega com os dados online e dos partidos e calcula um perfil. A partir desses dados "basta que a Cambridge Analytica impacte essa pessoa com a propaganda política perfeita - e super segmentada" (ALVES, 2017, s.p.). Observa-se a presente dinâmica em um exemplo baseado na discussão sobre o porte de arma, na qual se utiliza duas estratégias diversas, primeiramente para "uma audiência altamente neurótica" utiliza-se o recurso da "a ameaça de um roubo e a apólice de seguro de uma arma na mensagem'. Na hora, uma imagem mostra a mão de um intruso esmagando uma janela." (ALVES, 2017, s.p.) Agora quando se tem "um público que se preocupa com tradição, hábitos e família': outra imagem mostra um homem e uma criança de pé em um campo ao pôr do sol, ambos segurando armas, caçando patos." (ALVES, 2017, s.p.).

"Quase todas as mensagens publicadas por Trump foram baseadas em dados" (ALVES, 2017, s.p.), relatou o CEO da Cambridge Analytica, Alexander Nix, sendo que o investimento da campanha para tais serviços foi de 15 (quinze) milhões de dólares em pesquisas de tal empresa.

Além disso, um documento interno foi divulgado a funcionários explicando como que a empresa britânica auxiliou Donald Trump a vencer as eleições de 2016, usando plataformas digitais como o Google, Snapchat, Twitter, Facebook e YouTube. O documento de 27 páginas, elaborado por funcionários, mostra as técnicas utilizadas para direcionar mensagens nas redes sociais de forma a alcançar os eleitores certos, de maneira a favorecer o voto no candidato republicano, por meio de tratamento intensivo de dados coletados e algoritmos desenvolvidos para enviar 10 mil mensagens para grupos de pessoas distintos, meses antes das eleições. Segundo a apresentação da Cambridge Analytica, os anúncios foram visualizados milhares de milhões de vezes (DIÂRIO DE NOTÍCIA, 2018, s.p.).

16 Na década de 1980, duas equipes de psicólogos desenvolveram um modelo que buscava avaliar pessoas com base em cinco traços de personalidade - o modelo foi chamado de Big Five: abertura (a novas experiências), consenciosidade (perfeccionismo), extroversão (sociabilidade), condescendência (cooperatividade) e neuroticismo (temperamento). Com base nessas dimensões - conhecidas pela sigla em inglês OCEAN - é possível fazer uma avaliação relativamente precisa de qualquer pessoa. Isso inclui necessidades e medos e como eles devem se comportar. O Big Five tornou-se a técnica padrão de psicometria. ALVES, Paulo. BIG DATA: o segredo por trás da eleição de Trump. SHOW ME TECH. o6/o2/2017. Disponível em: <https://www.showmetech.com.br/big-data-trump/>. Acesso em: 02 dez. 2019. 
A Cambridge Analytic não elaborou nada ilegal, mas, teve acesso a dados de mais de 50 milhões de usuários do Facebook, permitindo desenvolver algoritmos para categorizar, de acordo com o seu perfil, e atingir diferentes grupos de usuários. Inclusive, o uso da plataforma Youtube auxiliou sob aspectos geográficos. A campanha de Trump mostrou dois anúncios diferentes, de acordo com o tipo de eleitores, segundo a informação geográfica disponível. "Para os eleitores que residiam em áreas 'vermelhas', ou seja, onde era mais provável votarem Trump, foi mostrada 'uma imagem triunfante do candidato', com conselhos de como poderiam votar". Já nas áreas que podiam conter indecisos, os usuários "viam uma imagem diferente: de apoiantes famosos do republicano” (DIÁRIO DE NOTÍCIA, 2018, s.p.).

Pelo Twitter, aqueles eleitores que seguiam Trump podiam partilhar tweets favoráveis ao candidato usando hashtags pré-estabelecidas. Foi usada também a publicidade paga do Google, ou seja, para dar a quem pesquisava determinados temas, como, por exemplo 'Trump Iraque guerra', os resultados colhidos eram sempre em destaques para favorecer à campanha (DIÁRIO DE NOTÍCIA, 2018, s.p.).

Percebe-se que de fato as TIC's são instrumentos fortes e quando usadas em prol da sociedade os resultados capacitam as expansões de liberdade. Porém, a Internet deve trazer aos usuários não apenas a sensação de conforto e praticidade, mas precisa também proporcionar a efetivação da transparência na participação popular de processos democráticos digitais, garantindo que todas as informações cheguem aos usuários. Isto, para evitar que, mesmo quando conquistado o acesso por todos, não se tenha um espaço de manipulações, ferindo preceitos e garantias de direitos fundamentais.

\section{CONSIDERAÇÕES FINAIS}

O artigo analisou a democracia digital, suas características e possibilidades de manipulação, verificando problemas não resolvidos mesmo frente a existência de novas tecnologias acerca da participação política do cidadão.

A atual estrutura da Internet revela hostilidades graves aos direitos fundamentais basilares, pressupostos de um sistema efetivamente democrático. Mesmo porque, existe uma concentração de poder nas empresas que tem por objeto central o conjunto de dados pessoais de seus usuários, a exemplo das redes sociais, o que levanta dúvidas sobre a possibilidade de se verificar a efetivação dos princípios da democracia participativa no ambiente digital.

As TIC's abrem novas possibilidades da atuação dos diversos personagens na concretização da democracia, agora em novo espaço, o digital. Espaço esse em que surge a ampliação das possibilidades já que a presença física não se faz necessária para debates nem para votar. Porém, não se pode esquecer de que é necessário buscar meios de inclusão de todos no espaço digital, uma vez que com o surgimento de novas tecnologias, em especial das TIC's, percebe-se a possibilidade do cidadão manifestar-se na Internet, usando as redes sociais, propagando pensamentos, informações e opiniões; bem como exercendo pressão no Poder Público para que medidas sejam tomadas em relação aos mais variados temas.

Tal movimentação no espaço digital fez surgir um novo cidadão, que conectado, exerce a chamada democracia digital. A tecnologia aliada ao conhecimento e à propagação de informações é uma ferramenta para o desenvolvimento e concretização da democracia representativa. Desse modo, as TIC's e as redes sociais estabelecem um canal pelo qual os usuários podem não somente exibir suas vidas sociais, mas efetivamente se expressar em assuntos envolvendo política, escândalos e corrupção, inclusive unindo-se e mobilizando-se em grande quantidade de pessoas por meio do mundo digital para agirem no mundo "real". 
Diante disso, as redes sociais vislumbraram uma nova dimensão ao cidadão: participar da vida política do país.

Assim, surgem inúmeras questões e problemas a serem enfrentados, em especial quanto ao exercício de uma democracia verdadeira, no sentido dos usuários não apenas serem influenciados, mas efetivamente participarem e fiscalizarem questões políticas de acordo com suas opiniões livres. Um espaço com cidadãos educados e conscientes sobre as discussões e informações verdadeiras e fidedignas, garantindo a compreensão dos temas propostos à discussão, com inclusão de todos (inclusão digital), apesar de parecer utópico, pode um dia se concretizar.

Porém, o que se percebe hoje é que a sociedade em rede é uma estrutura dinâmica altamente flexível às pressões sociais, culturais, políticas, ambientais e econômicas. O que permanece em todos os casos é o domínio da 'grande rede' sobre as atividades e pessoas, sejam estas internas ou externas às redes.

Para concretizar a democracia digital deve-se aliar o desenvolvimento tecnológico à uma educação efetiva, em especial voltada ao mundo digital, a fim de que a Internet possa criar uma nova possibilidade de participação democrática do cidadão. Sendo tal cidadão um novo sujeito que efetivamente, reflete, fiscaliza e participa das questões que afligem os anseios sociais, auxiliando na concretização da democracia. Também, por isso tem-se um movimento mundial voltado à novas leis e regramentos para proteção de dados pessoais dos usuários, de modo a coibir que, por meio de algoritmos, cidadãos-usuários sejam influenciados de maneira velada ao usarem redes sociais, e principalmente, quando o assunto esteja relacionado ou fere a democracia.

As Tecnologias da Informação e Comunicação transformaram de maneira significativa o comportamento dos cidadãos, instituições públicas e privadas. Evidentemente que com a participação do cidadão na vida política e democrática, portanto, não foi diferente. A Internet deve proporcionar a efetivação da transparência e participação popular, promovendo um ambiente saudável ao debate público, neutro e seguro. Caso contrário, está-se diante apenas de uma nova ferramenta de alienação e manipulação do cidadão.

\section{REFERENNCIAS}

ALVES, Paulo. BIG DATA: o segredo por trás da eleição de Trump. SHOW ME TECH. 06/02/2017. Disponível em: <https://www.showmetech.com.br/big-data-trump/>. Acesso em: o2 dez. 2019.

BAUMAN, Zygmunt. Em busca da política. Tradução de: Marcus Penchel. Rio de Janeiro: Jorge Zahar, 2000.

BRASIL. Câmara dos Deputados. E-Democracia. Sobre o portal e-democracia. Disponível em: <http://arquivo.edemocracia.camara.leg.br/web/public/o-que-e\#.WOEzKgIrLbo >. Acesso em: 02 dez. 2019.

BRASIL. Lei 12.965/2014. Marco Civil da Internet. Estabelece princípios, garantias, direitos e deveres para o uso da Internet no Brasil.

CASTELLS, Manuel. A galáxia Internet: reflexões sobre Internet, negócios e sociedade. Tradução de: Rita Espanha. 2. ed. Lisboa: Fundação Calouste Gulbenkian, 2007. 
CASTELLS, Manuel. A sociedade em rede. 2. ed. São Paulo: Paz e Terra, 1999.

CASTELLS, Manuel. Redes de indignação e esperança: movimentos sociais na era da Internet. Rio de Janeiro: Zahar, 2013.

CELLAN-JONES, Rory. Como o Facebook pode ter ajudado Trump a ganhar a eleição. BBC. 12 nov. 2016. Disponível em: <https://www.bbc.com/portuguese/geral-37961917>. Acesso em: o2 dez. 2019.

CHEVALLIER, Jacques. O Estado pós-moderno. Belo Horizonte: Fórum, 2009.

DAHL. Robert A. Sobre a democracia. Tradução de: Beatriz Sidou. Brasília: Editora Universidade de Brasília, 2011.

DIÁRIO DE NOTÍCIAS. O documento que explica como a Cambridge Analytica ajudou a eleger Trump. 26/o3/2018. Disponível em: $<$ https://www.dn.pt/mundo/como-a-cambridgeanalytica-ajudou-na-eleicao-de-trump-9209379.html>. Acesso em: 02 dez. 2019.

FREITAS, Cinthia Obladen de Almendra. A Vulnerabilidade do Consumidor e a Exposição Pública na Internet. In: ROVER, Aires José; GALINDO, Fernando (Orgs.). III Encontro de Internacionalização do CONPEDI. Universidade Complutense de Madrid. Madrid/Espanha: Ediciones Laborum, v. 9, pp. 76-101, 2015.

GABARDO, Emerson. Princípio constitucional da eficiência. São Paulo: Dialética, 2002.

GREENFIELD, Adam. Everyware: The dawning age of ubiquitous computing. New Riders, CA, 2006.

HINDMAN, Matthew. The myth of digital democracy. Princeton: Princeton University Press, 2009.

HIRST, Paul. A democracia representativa e seus limites. Tradução de: Maria Luiza X. de A. Borges. Rio de Janeiro: Jorge Zahar Editor, 1992.

LINKEDLN. Sobre. Disponível em: <https://br.linkedin.com/>. Acesso em: 02 dez. 2019.

MBL. Movimento Brasil Livre. Sobre. Disponível em: <http://www.movimentobrasillivre. org/>. Acesso em: 02 dez. 2019.

MOVIMENTO Vem Pra Rua. Sobre. Disponível em: <http://vemprarua.net>. Acesso em: o2 dez. 2019.

MPL. Movimento Passe Livre. Sobre. Disponível em: <https://www.facebook.com/passelivresp>. Acesso em: 02 dez. 2019.

NAÇÕES UNIDAS. Comissão Econômica para a América Latina e o Caribe. CEPAL. Panorama Social da América Latina. Síntese. 2014. Disponível em: <https://repositorio.cepal.org/ bitstream/handle/11362/37706/1/S1420848_pt.pdf>. Acesso em: 02 dez. 2019. 
NINO, Carlos Santiago. Los escritos de Carlos S. Nino: derecho, moral y politica. Buenos Aires: Gedisa, 2007.

OXFORD Living Dictionaries. Definition of post-truth. Disponível em: <https:// en.oxforddictionaries.com/definition/post-truth>. Acesso em: 02 dez. 2019.

PAMPLONA, Danielle Anne; FREITAS, Cinthia Obladen de Almendra. Exercício democrático: a tecnologia e o surgimento de um novo sujeito. Revista Pensar, Fortaleza, v. 20, n. 1, pP. 82105, jan./abr. 2015.

PARISER, Eli. O filtro invisível. O que a Internet está escondendo de você. Tradução: Diego Alfaro. Rio de Janeiro: Zahar, 2012.

RECUERO, Raquel. Diga-me com quem falas e dir-te-ei quem és: a conversação mediada pelo computador e as redes sociais na Internet. Revista FAMECOS, Porto Alegre, n. 38, abr. 2009.

SEN, Amartya. Desenvolvimento como Liberdade. São Paulo: Companhia das Letras, 2000.

VAIDHYANATHAN, Siva. The googlization of everything (and why should we worry). Berkeley: University of California Press, 2011.

WU, Tim. Impérios da comunicação. Do telefone à Internet, da AT\&T ao Google. Tradução: Cláudio Carina. Rio de Janeiro: Zahar, 2012. 